\title{
Visible Lasers and Emerging Color Converters for Lighting and Visible Light Communications
}

\author{
Chao Shen \\ Photonics Laboratory, King Abdullah University of Science and Technology (KAUST), Thuwal 21534, Saudi Arabia \\ E-mail address: chao.w.shen@gmail.com
}

\begin{abstract}
GaN-based lasers are promising for white lighting and visible-light communication (VLC). The advances of III-nitride photonic integration, and the application of YAG crystal and perovskite-based phosphors to lighting and VLC will be discussed.

OCIS codes: (060.2605) Free-space optical communication; (140.7300) Visible lasers; (230.3670) Light-emitting diodes; (230.5590) Quantum-well, -wire and -dot devices; (250.0250) Optoelectronics; (250.5960) Semiconductor lasers.
\end{abstract}

The past decade witnessed the rapid development of III-nitride light-emitting diodes (LEDs) [1, 2], superluminescent diodes (SLDs) [3, 4], and laser diodes (LDs) [5, 6], for solid-state lighting (SSL), visible-light communication (VLC), optical storage, and internet-of-things (IoT) [7, 8]. InGaN/GaN quantum well (QW)-based LEDs have been established as the fundamental component for SSL applications while recent studies suggested that the GaN-based LDs, which is free from efficiency droop, may outperform LEDs as a viable high-power light source [9, 10]. Meanwhile, there are increasing potentials in using such emitters in visible-light based optical communication systems for indoor and outdoor applications as data-rate demands are exponentially growing in the near future $[8,11,12]$. Since LDs exhibit significantly larger modulation bandwidth than LEDs, VLC links based on GaN lasers have shown multiple gigabit per second (Gbps) data rate, suggesting its growing potential for SSL-VLC dual-functionality applications $[12,13]$. The development of devices and components in laser-based white lighting and data communication systems will be discussed.

Similar to the structure in white LEDs, laser white light bulb can be constructed by employing a blue laser exciting yellow phosphor as the color converter. A correlated color temperature (CCT) of $\sim 4000 \mathrm{~K}$ and a color rendering index (CRI) of $\sim 57$ has been achieved using a $450-\mathrm{nm}$ emitting LD and YAG:Ce phosphor [13, 14]. The CRI and CCT can be further improved or engineered by using combinations of violet-blue LDs with a mixture of two or more color converters. For example, a CCT of $\sim 2700 \mathrm{~K}$ and a CRI of $>90$ has been reported using a violet LD exciting a mixture of red-, green-, and blue-emitting (RGB) phosphors [14]. By using a blue LD with novel $\mathrm{CsPbBr}_{3}$ perovskite nanocrystals (NCs) with conventional red phosphor as the color converter, a CRI of $\sim 89$ and a CCT of $\sim 3200 \mathrm{~K}$ has been achieved [15]. Apart from the white light characteristics including CRI and CCT, the conversion efficiency and stability of color converters are of particular interest due to a significantly higher excitation power density in LD based white lighting [16]. Hence, the utilization of YAG:Ce single crystal phosphor plate has been investigated for high power laser based SSL lamp reaching a peak luminous flux of $1100 \mathrm{~lm}$ [17]. Ceramic YAG:Ce yellow phosphor plates have also been developed for efficient white light conversion under high power blue radiant flux density of 19.1 $\mathrm{W} / \mathrm{mm}^{2}$ [18]. The YAG crystal and perovskite-based phosphors offer new opportunities for the future of laser based high brightness lighting. Further investigations on effects of the surface morphology, diffusing element and shape of the color converter are important in engineering the white light beam excited by focused high power violet-blue lasers.

The utilization of white light for VLC, or "Li-Fi", has attracted increasing research interest owing to the growing demand for high-speed data links $[8,11]$. We have demonstrated 2 Gbps data transmission of unfiltered white light generated by direct modulation of a blue GaN LD exciting YAG phosphor using a non-return-to-zero on-off keying (NRZ-OOK) modulation scheme [19]. A 3-dB modulation bandwidth of $1.1 \mathrm{GHz}$ was measured without a limitation from the slow 3.8 MHz phosphor response, which is significantly higher than that in conventional LEDs. High-speed data communication link based on white light generated using a violet LD pumping RGB phosphors was also demonstrated recently [20]. Further investigations show that both GaN-based edge emitting laser diodes (EELDs) and vertical-cavity surface-emitting lasers (VCSELs) exhibit beyond GHz modulation bandwidth [21, 22]. Though the micro-pixel LEDs have shown enhanced modulation characteristics compared to the broad-area counterparts, their output powers are relatively low, making it less attractive for high brightness applications [23, 24]. Therefore, the GaN laser-based VLC will play an important part in free space optical communications.

To date, the smart lighting and VLC functionalities have been demonstrated based on discrete devices, such as IIInitride LDs, transverse-transmission modulators, and planar photodetectors [25, 26]. We have studied the monolithic integration of LDs together with modulators, amplifiers, and detectors, for VLC applications. Such on-chip integration offers a number of advantages, including small-footprint, high-speed, and low power consumption. A blue-emitting 
integrated waveguide modulator-laser diode (IWM-LD) has been designed on a semipolar (20) $\overline{21}$ )-plane GaN substrate [27]. The IWM-LD show a high modulation efficiency of $2.68 \mathrm{~dB} / \mathrm{V}$. A large extinction ratio of $11.3 \mathrm{~dB}$ is measured in the violet-emitting IWM-LD [28]. Utilizing the integrated modulator, Gbps data communication was demonstrated using OOK modulation scheme. In addition, we fabricated the 404-nm emitting integrated shortwavelength semiconductor optical amplifier (SOA) - laser diode, showing a large gain of $5.32 \mathrm{~dB}$ at $6 \mathrm{~V}$ [29]. Such device can also be utilized in the modulated amplifier scheme enabling high-speed modulation. Since the signal detection is another important component in VLC system, we have fabricated and characterized the high-performance waveguide photodetector (WPD) integrated LD at $405 \mathrm{~nm}$ [30]. A significant large modulation bandwidth of $230 \mathrm{MHz}$ is measured in the WPD and can be further improved by reducing the RC-time constant. Both the WPD and LD are sharing the single active region, making it promising to build VLC transceiver on single laser chip. The seamlessly integrated elements enable photonic IC at the visible wavelength for many critical applications, such as smart lighting and display, free-space and underwater optical communications, optical switching, clocking, and interconnect [20, 3133].

In summary, the paper presents the advances and challenges of laser based SSL-VLC systems. The design, fabrication, and characterization of III-nitride laser based photonic integration and emerging color converters for lighting and data communication are discussed. The results suggest that the laser-based solution is a promising approach towards next generation high-brightness smart lighting and high-speed visible-light communications.

\section{References}

[1]. H. Masui, S. Nakamura, S. P. DenBaars, and U. K. Mishra, "Nonpolar and Semipolar III-Nitride Light-Emitting Diodes: Achievements and Challenges," IEEE Trans. Electron Dev. 57, 88-100 (2010).

[2]. C. Shen, T. K. Ng, and B. S. Ooi, "Enabling area-selective potential-energy engineering in $\mathrm{InGaN} / \mathrm{GaN}$ quantum wells by post-growth intermixing," Opt. Express 23, 7991-7998 (2015).

[3]. C. Shen, T. K. Ng, J. T. Leonard, A. Pourhashemi, S. Nakamura, S. P. DenBaars, J. S. Speck, A. Y. Alyamani, M. M. El-Desouki, and B. S. Ooi, "High-brightness semipolar $(20 \overline{21})$ blue $\mathrm{InGaN} / \mathrm{GaN}$ superluminescent diodes for droop-free solid-state lighting and visible-light communications," Opt. Lett. 41, 2608-2611 (2016).

[4]. C. Shen, C. Lee, T. K. Ng, S. Nakamura, J. S. Speck, S. P. DenBaars, A. Y. Alyamani, M. M. El-Desouki, and B. S. Ooi, "High-speed 405nm superluminescent diode (SLD) with 807-MHz modulation bandwidth," Opt Express 24, 20281-20286 (2016).

[5]. M. T. Hardy, D. F. Feezell, S. P. DenBaars, and S. Nakamura, "Group III-nitride lasers: a materials perspective," Mater. Today 14, 408-415 (2011).

[6]. A. Tian, J. Liu, L. Zhang, Z. Li, M. Ikeda, S. Zhang, D. Li, P. Wen, F. Zhang, Y. Cheng, X. Fan, and H. Yang, "Green laser diodes with low threshold current density via interface engineering of InGaN/GaN quantum well active region," Opt. Express 25, 415-421 (2017).

[7]. S. Pimputkar, J. S. Speck, S. P. DenBaars, and S. Nakamura, "Prospects for LED lighting," Nat. Photonics 3, 180-182 (2009).

[8]. D. Tsonev, S. Videv, and H. Haas, "Towards a $100 \mathrm{~Gb} / \mathrm{s}$ visible light wireless access network," Opt. Express 23, 1627-1637 (2015).

[9]. J. J. Wierer and J. Y. Tsao, "Advantages of III-nitride laser diodes in solid-state lighting," Phys. Status Solidi A 212, 980-985 (2015).

[10]. J. Y. Tsao, M. H. Crawford, M. E. Coltrin, A. J. Fischer, D. D. Koleske, G. S. Subramania, G. T. Wang, J. J. Wierer, and R. F. Karlicek, "Toward smart and ultra-efficient solid-state lighting," Adv. Opt. Mater. 2, 809-836 (2014).

[11]. D. Karunatilaka, F. Zafar, V. Kalavally, and R. Parthiban, "LED based indoor visible light communications: state of the art," IEEE Commun. Surv. Tut. 17, 1649-1678 (2015).

[12]. Y.-C. Chi, D.-H. Hsieh, C.-T. Tsai, H.-Y. Chen, H.-C. Kuo, and G.-R. Lin, "450-nm GaN laser diode enables high-speed visible light communication with 9-Gbps QAM-OFDM," Opt. Express 23, 13051-13059 (2015).

[13]. C. Lee, C. Shen, H. M. Oubei, M. Cantore, B. Janjua, T. K. Ng, R. M. Farrell, M. M. El-Desouki, J. S. Speck, S. Nakamura, B. S. Ooi, and S. P. DenBaars, "2 Gbit/s data transmission from an unfiltered laser-based phosphor-converted white lighting communication system," Opt. Express 23, 29779-29787 (2015).

[14]. K. A. Denault, M. Cantore, S. Nakamura, S. P. DenBaars, and R. Seshadri, "Efficient and stable laser-driven white lighting," AIP Advances 3, 072107 (2013).

[15]. I. Dursun, C. Shen, M. R. Parida, J. Pan, S. P. Sarmah, D. Priante, N. Alyami, J. Liu, M. I. Saidaminov, M. S. Alias, A. L. Abdelhady, T. K. Ng, O. F. Mohammed, B. S. Ooi, and O. M. Bakr, "Perovskite nanocrystals as a color converter for visible light communication," ACS Photonics 3, 1150-1156 (2016).

[16]. J. J. Wierer, J. Y. Tsao, and D. S. Sizov, "Comparison between blue lasers and light-emitting diodes for future solid-state lighting," Laser Photon. Rev. 7, 963-993 (2013).

[17]. M. Cantore, N. Pfaff, R. M. Farrell, J. S. Speck, S. Nakamura, and S. P. DenBaars, "High luminous flux from single crystal phosphorconverted laser-based white lighting system," Opt. Express 24, A215-A221 (2016).

[18]. Y. H. Song, E. K. Ji, B. W. Jeong, M. K. Jung, E. Y. Kim, and D. H. Yoon, "High power laser-driven ceramic phosphor plate for outstanding efficient white light conversion in application of automotive lighting," Sci. Rep. 6, 31206 (2016).

[19]. C. Lee, C. Shen, H. M. Oubei, M. Cantore, B. Janjua, T. K. Ng, R. M. Farrell, M. M. El-Desouki, J. S. Speck, S. Nakamura, B. S. Ooi, and S. P. DenBaars, "2 Gbit/s data transmission from an unfiltered laser-based phosphor-converted white lighting communication system," Opt. Express 23, 29779-29787 (2015).

[20]. C. Lee, C. Shen, C. Cozzan, R. M. Farrell, J. S. Speck, S. Nakamura, B. S. Ooi, and S. P. DenBaars, "Gigabit-per-second white light-based visible light communication using near-ultraviolet laser diode and red-, green-, and blue-emitting phosphors," Opt. Express 25, 17480-17487 (2017).

[21]. C. Lee, C. Zhang, D. L. Becerra, S. Lee, C. A. Forman, S. H. Oh, R. M. Farrell, J. S. Speck, S. Nakamura, J. E. Bowers, and S. P. DenBaars, "Dynamic characteristics of $410 \mathrm{~nm}$ semipolar (2021) III-nitride laser diodes with a modulation bandwidth of over $5 \mathrm{GHz}$," Appl. Phys. Lett. 109, 101104 (2016). 
[22]. C. Shen, J. T. Leonard, E. C. Young, T. K. Ng, S. P. DenBaars, J. S. Speck, S. Nakamura, A. Y. Alyamani, M. M. El-Desouki, and B. S. Ooi, "GHz modulation bandwidth from single-longitudinal mode violet-blue VCSEL using nonpolar InGaN/GaN QWs," in Conference on Lasers and Electro-Optics, OSA Technical Digest (Optical Society of America, 2016), pp. STh1L.2.

[23]. C. Shen, T. K. Ng, Y. Yang, D. Cha, and B. S. Ooi, "InGaN micro-LED-pillar as the building block for high brightness emitters," in Proceedings of IEEE Photonics Conference (Institute of Electrical and Electronics Engineers, 2013), pp.174-175.

[24]. D. Tsonev, H. Chun, S. Rajbhandari, J. J. D. McKendry, S. Videv, E. Gu, M. Haji, S. Watson, A. E. Kelly, G. Faulkner, M. D. Dawson, H. Haas, and D. O'Brien, "A 3-Gb/s single-LED OFDM-based wireless VLC link using a Gallium Nitride $\mu$ LED," IEEE Photon. Technol. Lett. 26, 637-640 (2014).

[25]. E. Sari, L. W. Jang, J. H. Baek, I. H. Lee, X. W. Sun, and H. V. Demir, "Dislocation density dependent electroabsorption in epitaxial lateral overgrown InGaN/GaN quantum structures," Opt. Express 21, 1128-1136 (2013).

[26]. Z. Y. Jiang, M. R. M. Atalla, G. J. You, L. Wang, X. Y. Li, J. Liu, A. M. Elahi, L. Wei, and J. Xu, "Monolithic integration of nitride light emitting diodes and photodetectors for bi-directional optical communication," Opt. Lett. 39, 5657-5660 (2014).

[27]. C. Shen, T. K. Ng, J. T. Leonard, A. Pourhashemi, H. M. Oubei, M. S. Alias, S. Nakamura, S. P. DenBaars, J. S. Speck, A. Y. Alyamani, M. M. Eldesouki, and B. S. Ooi, "High-modulation-efficiency, integrated waveguide modulator-laser diode at $448 \mathrm{~nm}$," ACS Photonics 3, 262-268 (2016).

[28]. C. Shen, C. Lee, T. K. Ng, J. S. Speck, S. Nakamura, S. P. DenBaars, A. Y. Alyamani, M. M. Eldesouki, and B. S. Ooi, "GHz modulation enabled using large extinction ratio waveguide-modulator integrated with $404 \mathrm{~nm} \mathrm{GaN}$ laser diode," in Proceedings of IEEE Photonics Conference (Institute of Electrical and Electronics Engineers, 2016), pp. 813-814.

[29]. C. Shen, C. Lee, T. K. Ng, S. Nakamura, J. S. Speck, S. P. DenBaars, A. Y. Alyamani, M. M. El-Desouki, and B. S. Ooi, "High gain semiconductor optical amplifier - Laser diode at visible wavelength," in Proceedings of IEEE International Electron Devices Meeting (IEDM) (Institute of Electrical and Electronics Engineers, 2016), pp. 22.24.21-22.24.24.

[30]. C. Shen, C. Lee, E. Stegenburgs, J. H. Lerma, T. K. Ng, S. Nakamura, S. P. DenBaars, A. Y. Alyamani, M. M. El-Desouki, and B. S. Ooi, "Semipolar III-nitride quantum well waveguide photodetector integrated with laser diode for on-chip photonic system," Appl. Phys. Express 10, 042201 (2017).

[31]. C. Shen, Y. Guo, H. M. Oubei, T. K. Ng, G. Liu, K.-H. Park, K.-T. Ho, M.-S. Alouini, and B. S. Ooi, "20-meter underwater wireless optical communication link with 1.5 Gbps data rate," Opt. Express 24, 25502-25509 (2016).

[32]. M. Tchernycheva, A. Messanvi, A. D. Bugallo, G. Jacopin, P. Lavenus, L. Rigutti, H. Zhang, Y. Halioua, F. H. Julien, J. Eymery, and C. Durand, "Integrated Photonic Platform Based on InGaN/GaN Nanowire Emitters and Detectors," Nano Letters 14, 3515-3520 (2014).

[33]. W. Cai, Y. C. Yang, X. M. Gao, J. L. Yuan, W. Yuan, H. B. Zhu, and Y. J. Wang, "On-chip integration of suspended InGaN/GaN multiplequantum-well devices with versatile functionalities," Opt. Express 24, 6004-6010 (2016). 